\title{
An integrated job stress model in workplace
}

\author{
Y. H. Lee ${ }^{1}$, S. D. Lee ${ }^{1}$, Y. S. Kim ${ }^{2}$ \\ ${ }^{1}$ Department of Industrial Management Engineering, Dong-A University, Busan, Korea \\ ${ }^{2}$ Department of Human Ecology, Kyungsung University, Busan, Korea \\ yonghee@donga.ac.kr
}

\begin{abstract}
This paper evaluates stress factors to effect on jobs and develops the evaluation model to apply the ma nufacturing workplaces. There are many psychosocial approaches and risk assessment tools to evaluate a job stress and muscularskeletal complaints that are attributed to hazardous occupations, but the exact etiology of these stress/disorders are currently unclear. The researches, however, indicate that these problems are multi-factorial and complicated with physical, psychosocial and environmental factors. Therefore we developed the integrated model considering those factors for the job stress evaluation in manufacturing workplaces.
\end{abstract}

Keywords: job stress, muscularskeletal disorders, psychosocial factors, integrated job stress questionnaire

\section{Introduction}

The issue of job stress and ergonomic assessment of risk factors associated with musculoskeletal injuries have received much attention from researchers and practitioners for years, and a number of methodologies have been studied in the research community. Job stress due to downsizing and restructuring the company leads to develop both mental disorder and physical illness of Korean workers. It is strongly required that systemic studies to grasp the whole picture of current situation for job stress and to clarify its associated risk factors should be performed.

Although the level of job stress and the detailed risk factors may vary, risk assessment methods can be categorized into two groups: macro-ergonomic and micro-ergonomic risk assessment. Limited research has been conducted with respect to development and testing of macro-risk assessment procedures (Lin et al., 1996). The use of such techniques will become an important component of a health surveillance process due to the anticipated promulgation of ergonomic standards in various countries around the world.

Over the past 20 years, a number of researchers have raised concerns regarding the reliance on self-reports of psychosocial work conditions for measuring job strain (Frese and Zapf, 1988; Kasl, 1978, $1987,1998)$. One hundred and forty supervisors in 18 different departments used the job contents questionnaire (JCQ, Karaseck, 1985) to estimate psychosocial work conditions for the jobs of 8,838 civil servants. Based on this investigation, men and women with self-reported low-job-control had about 1.5 to 1.9 times for the risk of developing new CHD compared with participants with high control (Ostry et al., 2001). Also, Keyserling et al. (1992) developed a checklist to identify the risk factors for awkward postures of legs, trunk and neck of a participant. Keyserling et al. (1993) designed another checklist to assess risks for upper extremity cumulative trauma disorders. In order to assess ergonomic stresses in the workplace, Lin et al.
(1996) developed a macro-ergonomic risk assessment tool. Macro-ergonomic approach implies the consideration of the organizational/social, technological and physical work related subsystems (O'Neil, 1998).

Many researchers studied and developed a checklist related to work-related muscular skeletal disorders (WMSDs), cumulative trauma disorders (CTDs) and work-related upper extremity (WRUE) symptoms. The exact etiology of these symptoms/disorders is currently unclear. The research, however, indicates that this problem is multi-factorial in development and therefore likely to be complicated in terms of prevention and treatment (National Research Council and the Institute of Medicine, 2001; Deveraux et al., 2002). There are also psychosocial approaches, such as job content questionnaire (JCQ), generic job stress questionnaire (GJSQ) and macro-ergonomic risk assessment tool to enhance workers' safety and health. However, they are not different looking at the job stress from a holistic angle because an organization, human and the relationship between human and an organization are so organismic. Therefore we developed the integrated model considering psychosocial, physiological and environmental factors for job stress evaluation in manufacturing workplace.

\section{Method and material}

As shown in Table 1, various stress factors from JCQ, GJSQ, Jang's questionnaire, O'Neil's checkpoints and the proposed integrated job stress questionnaire (IJSQ) can be classified by three factors (i.e., physical, psychosocial, environmental factors). Although the majority of previous studies concentrated on psychosocial and few environmental factors, physical factors were not often incorporated into job stress. For example, JCQ consisted psychosocial factors, GJSQ considered psychosocial and environmental factors, O'Neil's checkpoints dealed with psychosomatic and physiological stress for office workers. However, the proposed IJSQ incorporates all physical, psychosocial 
and environmental factors. For verification purposes, an evaluation of the relationships among those factors should be performed. The proposed IJSQ composes various factors shown in Table 1 and checkpoints made from problem factors tree of O'Neil and consists 4 likert type questions including 6 items: (1) general factors, (2) physical factors, (3) psychosocial factors, (4) environmental factors, (5) evaluation of WMSDs, (6) job satisfaction. In this study, we investigated work environment and surveyed workers in manufacturing workplace to compare preceding questionnaires and IJSQ. The correlation analysis between physical, psychosocial, environmental factors and the evaluation of WMSDs was performed to evaluate factors affecting WMSDs.

The company consisting approximately 200 workers produces marine switchboards $(45 \%)$, control consoles $(35 \%)$ and thrusters $(20 \%)$ etc. The manufacturing processes include assembly (over $85 \%$ ), welding and painting. In order to estimate the results, we conduct a comparative study for the proposed IJSQ and other current methods using SPSS (ver 10.0).

Table 1 Stress Factors used in IJSQ

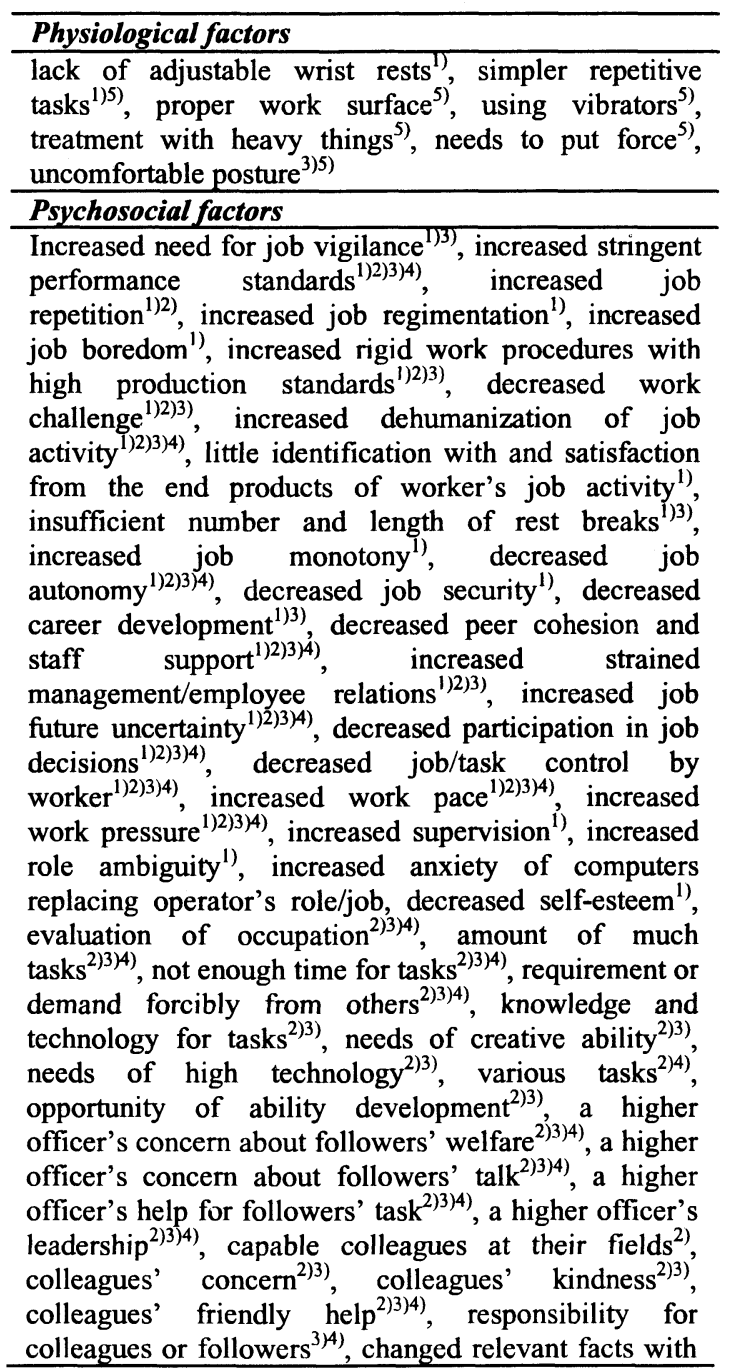

tasks often ${ }^{3 / 4)}$, fairness of personnel affair such as duty appraisement, promotion, positioning etc. ${ }^{3 / 4)}$, appropriateness of position compared with education and career $^{334)}$, job falling short of expectation ${ }^{3 / 4)}$, appropriateness of payment reflecting to an effort and achievement $^{334)}$, interest of present tasks ${ }^{3 / 4)}$, uncomfortable dining together ${ }^{3)}$, task indication without consistency ${ }^{34)}$, the atmosphere of the office with vertical authority ${ }^{3)}$, disadvantage from sexual difference $^{3)}$

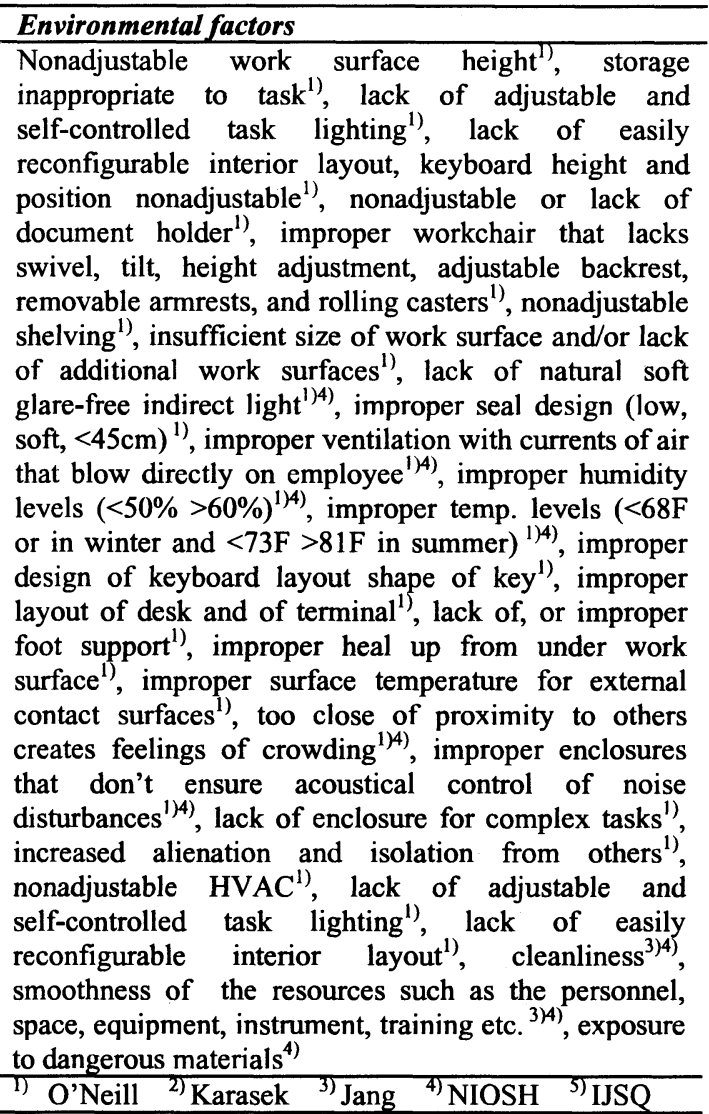

\section{Results}

Table 2 shows the basic statistics about the degree of job stress and the satisfaction of job in each questionnaire. The results of the proposed IJSQ and the current methods provide similar values in mean and S.D., same as the correlation analysis except JCQ $(\mathrm{p}=0.344)$. In case of JCQ, the correlation coefficient value was 0.217 and lower than the others. It might be resulted from the job characteristics in this study. The satisfaction of subjects is more affected by physical and environmental factors than psychosocial factors because all subjects are engaged in heavy work related to marines. As shown in Table 3 and Table 4, the possibility of the proposed IJSQ can be proved through the correlation analysis indicating IJSQ $(p=0.006)$ which is the second lowest $p$-value among five types of questionnaires and $p=0.0001$ which is the lowest p-value.

In the correlation analysis to evaluate factors affecting WMSDs (Table 5), the psychosocial $\left(0.595^{* *}\right)$ and the environmental $\left(0.487^{* *}\right)$ factors have influence on 
WMSDs. Namely, WMSDs are affected by not only physical factors but psyhosocial and environmental factors.

Table 2 The mean and S.D. of job stress and satisfaction

\begin{tabular}{c|c|c|c|c}
\hline \multirow{2}{*}{$\begin{array}{c}\text { Type of } \\
\text { questionnaire }\end{array}$} & \multicolumn{2}{|c|}{$\begin{array}{c}\text { The degree of } \\
\text { job stress }\end{array}$} & \multicolumn{2}{c}{$\begin{array}{c}\text { The satisfaction } \\
\text { of job }\end{array}$} \\
\cline { 2 - 3 } & Mean & S.D. & Mean & S.D. \\
\hline $\begin{array}{c}\text { Check list from } \\
\text { O'Neil }\end{array}$ & 2.69 & 0.38 & & \\
\hline JCQ & 2.47 & 0.24 & & \\
\hline Jang's quest. & 2.42 & 0.26 & \multirow{2}{*}{2.20} & \multirow{2}{*}{0.33} \\
\hline GJSQ & 2.43 & 0.25 & & \\
\hline IJSQ & 2.48 & 0.28 & & \\
\hline
\end{tabular}

Table 3 The result of Pearson's correlation analysis by the each evaluation model and job satisfaction

\begin{tabular}{c|c|c}
\hline $\begin{array}{c}\text { Type of } \\
\text { questionnaire }\end{array}$ & $\begin{array}{c}\text { Pearson's } \\
\text { coefficient }\end{array}$ & p-value \\
\hline O'Neil & $0.511^{*}$ & 0.018 \\
\hline JCQ & 0.217 & 0.344 \\
\hline Jang's quest. & $0.557^{* *}$ & 0.009 \\
\hline GJSQ & $0.648^{* *}$ & 0.001 \\
\hline IJSQ & $0.583^{* *}$ & 0.006 \\
\hline
\end{tabular}

Table 4 The result of Pearson's correlation analysis by the each evaluation model and WMSDs

\begin{tabular}{c|c|c}
\hline $\begin{array}{c}\text { Type of } \\
\text { questionnaire }\end{array}$ & $\begin{array}{c}\text { Pearson's } \\
\text { coefficient }\end{array}$ & p-value \\
\hline O'Neil & $0.7251^{* *}$ & 0.0002 \\
\hline JCQ & 0.2583 & 0.2583 \\
\hline Jang's quest. & $0.5828^{* *}$ & 0.0056 \\
\hline GJSQ & $0.6098^{* *}$ & 0.0056 \\
\hline IJSQ & $0.7462^{* *}$ & 0.0001 \\
\hline
\end{tabular}

Table 5 The result of Pearson's correlation analysis by the physical, psychosocial and environmental factors and WMSDs

\begin{tabular}{c|c|c}
\hline Factors & $\begin{array}{c}\text { Pearson's } \\
\text { coefficient }\end{array}$ & p-value \\
\hline Physical & $0.960^{* *}$ & 0.000 \\
\hline Psychosocial & $0.487^{*}$ & 0.025 \\
\hline Environmental & $0.595^{* *}$ & 0.004 \\
\hline
\end{tabular}

\section{Discussion}

In this paper, we proposed an IJSQ model utilizing various factors, which provided similar solutions to other current methods in basic statistics and correlation analysis. However, the proposed model was restricted to subjects who engaged in heavy work. For further research, it is needed to investigate various manufacture industry workers and measure the quantitative data using the physiological, psychological and epidemiological methods.

\section{Reference}

[1] Deveraux J.J., Vlachonikolis I.G., Buckle P.W.: Epidemiological study to investigate potential interaction between physical and psychosocial factors at work that may increase the risk of symptoms of musculoskeletal disorder of the neck and upper limb, Occupational and Environmental Medicine, 59(4): 269-277, 2002

[2] Karasek R., Gordon G., Pietrokovsky C. Rrese M., Pieper C., Schwartz J., Fry L., Schirer D.: Job Content Questionnaire: Questionnaire and user's guide, Lowell: University of Massachusetts, 1985

[3] Karasek R.A. and Theorell T.: Healthy Work: Stress, Productivity and the Reconstruction of Working Life, New York: Basic Books, 1990

[4] Kasl S.V.: Measuring job stressors and studying the health impact of the work environment: An epidemiologic commentary, J Occupational health Psychology. (3): 390-401, 1998

[5] Keller K., J. Corbett, D. Nichols: Repetitive strain injury in computer keyboard users: pathomechanics and trreatment principles in individual and group intervention, Journal of Hand Therapy, 11(1): 9-26, 1998

[6] Keyserling W. M., Brouwer, M. L. and Silverstein, B.: A checklist for evaluating ergonomic risk factors resulting from awkward postures of the legs, trunk and neck, Int J Industrial Ergonomics, (9): 283-301, 1992 [7] Keyserling W. M., Stetson D. S., Silverstein B. A. and Brouwer M. L.: A Checklist for evaluating ergonomic risk factors associated with upper extremity cumulative trauma disorders, Ergonomics, (36): 807-831, 1993

[8] Lin G., Ash G., Doran C., Kevin H.:

Macro-ergonomic risk assessment in nuclear remediation industry, Applied ergonomics, (27): 241-254, 1996

[9] Loisel, P., L. Gosselin, P. Durand, J. Lemaire, S. Poitras, L. Abenhaim: Implementation of a participatory ergonomics program in the rehabilitation of workers suffering from subacute back pain, Applied Ergonomics, (32): 53-60, 2001

[10] Marita C., Jan F. and Christer S.: Task design, psycho-social work climate and upper extremity pain disorderseffects of an organisational redesign on manual repetitive assembly jobs, Applied ergonomics, (30): 463-472, 1999

[11] Michael J. S. and Pascale C. S.: A balance theory of job design for stress reduction, International Journal of Industrial Ergonomics, (4): 67-79, 1989 